\title{
GENDER AND MINOR PSYCHIATRIC MORBIDITY: RESULTS OF A CASE-CONTROL STUDY IN A DEVELOPING COUNTRY*
}

\author{
EVANDRO DA SILVA FREIRE COUTINHO \\ Escola Nacional de Saúde Pública-Fiocruz; \\ Instituto de Medicina Social-UERJ and \\ National Research Council of Brazil (CNPq) \\ NAOMAR DE ALMEIDA FILHO \\ Instituto de Saúdo Coletiva-Universidade Federal da Bahia \\ and National Research Council of Brazil (CNPq) \\ JAIR DE JESUS MARI \\ Universidade Federal de São Paulo and \\ National Research Council of Brazil (CNPq) \\ LAURA C. RODRIGUES \\ London School of Hygiene and Tropical Medicine
}

\section{ABSTRACT}

Objective: Women suffer from minor psychiatric disorders (MPM) more frequently than men. Most of the studies were conducted in England and in the United States and some reported the higher occurrence of MPM among women to be modified by marital status and others by sociodemographic variables. The present study intends to address this question in a developing country. Method: A population based case-control study was conducted in three important urban centers in Brazil. Two hundred seventy-six individuals diagnosed as new cases of MPM and 261 controls were selected to investigate the role of a set of sociodemographic variables in the association between gender and MPM using logistic regression models. Results: Univariate analysis showed that women were more likely than men to suffer from MPM $(\mathrm{OR}=3.34 ; 2.27-4.91)$. After controlling for other sociodemographic variables, female gender was still positively associated

*This research received financial support from the Ministry of Health of Brazil, Pan-American Organization, FINEP, FAPERGS and National Research Council of Brazil (CNPq). 
with MPM, but not in a homogeneous way. A multiplicative interaction of gender with age group was found (LRT $=6.01 ; 2 \mathrm{df} ; p=0.05$ ) suggesting an increment in the magnitude of the association among those older than thirty years. Odds-ratios were 2.33 (1.19-4.55), 6.85 (2.86-16.41), and 7.47 (2.90-19.22) for age groups of fourteen to twenty-nine; thirty to forty-four; forty-five or more, respectively. There was no evidence of interaction of gender with marital status or other sociodemographic variables. Conclusions: The findings are consistent with the modification of the association between gender and MPM being mediated by social factors.

(Int'l. J. Psychiatry in Medicine 1999;29:197-208)

Key Words: anxiety disorders, case-control study, dysthymic disorder, phobic disorders, risk factors, sex, somatoform disorders

The greater prevalence of anxiety, affective, and somatoform disorders among women is probably the most consistent finding in psychiatric epidemiology [1-8]. Due to the difficulty in discriminating these non-psychotic disorders in community surveys, in many epidemiological studies they have been grouped under the labels of "common mental disorders" [9], or more frequently, "minor psychiatric morbidity (MPM)" [3, 10-12]. Although the later term does not reflect the degree of mental suffering or functional impairment associated with these diagnoses, we adopted this widely used terminology.

In a review of the literature, Gove [13] reported consistent findings of higher prevalence of mental illness in married women than in married men, but not in single women compared to single men. Other authors reported a similar pattern [2, 14-16].

Most of the studies concerned with the effect of marital status on the association between gender and the MPM were conducted in England and in the United States. Culture, society and its impact on MPM can be different in developing countries. The purpose of the present study is to explore how marital status and other sociodemographic factors modify the association between gender and MPM in three metropolitan areas of Brazil.

\section{MATERIALS AND METHODS}

\section{Study Population and Instruments}

This was a case-control study based on cases and controls selected in a two-stage population survey [17] conducted in 1991 in three cities in Brazil: Brasília, the capital of Brazil; São Paulo, the largest city in South America; and Porto Alegre, the capital of the State of Rio Grande do Sul. 
The first stage consisted in interviewing all subjects in a representative sample of the population over fourteen years old. The refusal rate was 10 percent. The instrument used in the first stage of the survey was the Questionnaire of Psychiatric Morbidity in Adults-QMPA [18] administered by lay-trained interviewers. Thirty percent of the people classified as positive according to QMPA and 10 percent of those classified as negative were selected into the second stage of the survey, with a refusal rate of 7 percent.

Trained psychiatrists interviewed all subjects included in the second stage using a Portuguese translation [19] of the Symptom Checklist of the 3rd version of the Diagnostic Statistical Manual of Mental Disorders-DSM-III [20].

\section{Selection of Cases and Controls}

All subjects interviewed in stage two with no lifetime reference of mental disorders in the DSM-III Symptom Checklist were considered as controls. Those diagnosed by the DSM-III as suffering from affective, anxiety, phobic or somatoform disorders (first symptoms in the previous 12 months) were considered as cases for the present investigation. Two hundred seventy-six individuals were defined as cases and 261 as controls. The remaining were excluded from this study. Almeida Filho et al. [17] provide a more detailed description of the survey design and data collection.

\section{Variables}

The main objective of this project was to study the association between gender and MPM and how this association was modified by: age (14 to 29; 30 to 44; 45 or more), educational level (low: primary school; high), marital status (single; married; widow/divorced), parity (no children under 14 years old; 1 to 2 children; 3 or more), being head of the family (self defined: yes or no), occupational status (employed; unemployed; housewife), internal migration (lifetime migration inside the country: yes or no) and city of residence (Brasília, São Paulo, Porto Alegre).

The dependent variable-minor psychiatric morbidity (MPM) includes the following diagnoses from the DSM-III Symptom Checklist:

1. Affective disorders: depression and dysthymia.

2. Anxiety disorders: generalized anxiety, post-traumatic disorder (acute and chronic), atypical anxiety disorder.

3. Phobic disorders: agoraphobia, social phobia, and simple phobia.

4. Somatoform disorders: somatization, conversion disorder, psychogenic pain disorder. 


\section{Data Analysis}

The analysis used the Epidemiological Graphics, Estimation and Testing Package [21]. An univariate analysis of the four diagnostic groups and gender was carried out (Table 1). After it was confirmed that the pattern of association was similar for the four diagnostic groups, all the subsequent analyses were performed grouping them under the label MPM.

At first, the association between gender and MPM was estimated by the crude odds-ratio (OR) and 95 percent confidence intervals. In order to control for the presence of joint confounding effect and to investigate the presence of effect modification, logistic models were built. We followed the strategy suggested by Kleinbaum [22], starting from a saturated model (including the exposure variable, the covariables and interaction terms). First, the presence of interaction (multiplicative scale) was evaluated comparing the saturated model to the one

Table 1. Associations between Affective, Anxiety, Phobic, and Somatoform Disorders and Sociodemographic Variables. Crude Odds-Ratios and Respective 95\% Confidence Intervals

\begin{tabular}{|c|c|c|c|c|}
\hline Variables & $\begin{array}{l}\text { Affective } \\
\text { Disorders }\end{array}$ & $\begin{array}{l}\text { Anxiety } \\
\text { Disorders }\end{array}$ & $\begin{array}{l}\text { Phobic } \\
\text { Disorders }\end{array}$ & $\begin{array}{l}\text { Somatoform } \\
\text { Disorders }\end{array}$ \\
\hline \multicolumn{5}{|l|}{ Gender } \\
\hline Male & 1 & 1 & 1 & 1 \\
\hline Female & $3.96(1.77-9.04)$ & $3.51(1.86-6.69)$ & $3.85(1.15-6.93)$ & 4.19 (1.93-9.27) \\
\hline \multicolumn{5}{|l|}{ Age Group } \\
\hline $14-29$ & 1 & 1 & 1 & 1 \\
\hline $30-44$ & $2.03(0.85-4.86)$ & $4.13(2$ 08-8.24) & $2.18(1.14-4.18)$ & $2.84(1.20-6.77)$ \\
\hline 45 or more & $1.43(0.66-3.11)$ & $1.65(0.84-3.26)$ & $1.40(0.76-2.59)$ & $1.90(0.83-4.41)$ \\
\hline \multicolumn{5}{|l|}{ Marital Status } \\
\hline Single & 1 & 1 & 1 & 1 \\
\hline Married & $1.84(0.74-4.64)$ & $1.77(0.96-3.27)$ & $1.74(0.89-3.39)$ & $2.00(0.93-4.36)$ \\
\hline Divorced/widow & $2.15(0.74-6.18)$ & $2.18(0.81-5.94)$ & $2.63(0.93-7.50)$ & $2.59(0.66-10.42)$ \\
\hline \multicolumn{5}{|l|}{ Parity } \\
\hline No children & 1 & 1 & 1 & 1 \\
\hline With children & $2.10(1.08-4.10)$ & $2.11(1.22-3.66)$ & $1.95(1.16-3.27)$ & $1.60(0.47-5.42)$ \\
\hline \multicolumn{5}{|l|}{ Education } \\
\hline High & 1 & 1 & 1 & 1 \\
\hline Low & $1.45(0.76-2.80)$ & $1.66(0.96-2.88)$ & $1.96(1.16-3.31)$ & $1.67(0.48-5.87)$ \\
\hline \multicolumn{5}{|l|}{ Migration } \\
\hline No & 1 & 1 & 1 & 1 \\
\hline Yes & $1.53(0.75-3.23)$ & $1.24(0.52-2.94)$ & $1.42(0.62-3.28)$ & $1.26(0.37-4.33)$ \\
\hline
\end{tabular}


without each interaction term (reduced model) through the likelihood ratio test (LRT). Only two-term interactions were analyzed. After that, the presence of confounding was investigated removing the covariables that were not part of the interaction term (hierarchy principle) [22], and comparing the new OR to the one obtained in the saturated model. The decision of keeping or dropping the covariables from the model was based on the magnitude of the change in the OR and the gain in terms of precision. Collinearity was investigated looking for changes in the standard errors of the estimated coefficients.

\section{RESULTS}

The distribution of the 276 cases and 261 controls, according to the categories of the variables, is presented in Table 2. Taking cases and controls together, women were about two times more frequent than men. The same difference was found for married people in relation to single ones. Widow and divorced categories showed small numbers. More than half of the study population have no children, and about two-third of the sample did not regard themselves as head of the family. People with low level of education were more common than those with higher level. Employment was found in 68 percent of the sample, and one-quarter were housewives. Migrants were highly prevalent. There were no important differences for the categories of the variable age group and place of residence.

According to the univariate analysis (Table 2) women were more likely than men to suffer from MPM (OR = 3.34; 2.27-4.91). When multivariate analysis was used, female gender was still positively associated with MPM, but not in a homogeneous way. The fact that all but one of the 95 percent confidence intervals presented in Table 3 do not include the null value $(\mathrm{OR}=1)$ shows that the association between gender and MPM is statistically significant within the strata of each sociodemographic variable. Nevertheless, a multiplicative interaction of gender with age group was suggested by the likelihood ratio test (LRT $=6.01$; $2 d f ; p=0.05$ ). The adjusted OR for the association between gender and MPM and respective $95 \%$ confidence intervals in each of the three categories of age are presented in Table 3, suggesting an increment in the magnitude of the association among those older than thirty years. Odds-ratios for age groups fourteen to twenty-nine, thirty to forty-four, and forty-five or more were 2.33 (1.19-4.55), 6.85 (2.86-16.41), and 7.47 (2.90-19.22), respectively.

The likelihood ratio test (LRT) [22] presented in Table 3 provides information about heterogeneity of the OR for this association (gender and MPM) among the strata of each socio-demographic variable. All the LRT, except for the interaction of gender with age group, had $p$-values above 0.20. So we cannot conclude the presence of multiplicative interaction of gender with the other sociodemographic variables. In summary, we found that women had higher risk of MPM than men, that it was more marked after thirty years of age and that there was no evidence 
202 / COUTINHO ET AL.

Table 2. Distribution of Cases and Controls According to Selected Sociodemographic Variables

\begin{tabular}{|c|c|c|c|c|c|c|c|}
\hline \multirow[b]{2}{*}{ Variables } & \multicolumn{2}{|c|}{ Total } & \multicolumn{2}{|c|}{ Cases } & \multicolumn{2}{|c|}{ Controls } & \multirow[b]{2}{*}{$P$-Value } \\
\hline & $N$ & $\%$ & $N$ & $\%$ & $N$ & $\%$ & \\
\hline \multicolumn{8}{|l|}{ Gender } \\
\hline Male & 171 & 31,8 & 54 & 19,6 & 117 & 44,8 & $<0.0001$ \\
\hline Female & 366 & 68,2 & 222 & 80,4 & 144 & 55,2 & \\
\hline \multicolumn{8}{|l|}{ Age Group } \\
\hline $14-29$ & 198 & 36,9 & 85 & 30,8 & 113 & 43,3 & 0.0005 \\
\hline $30-44$ & 163 & 30,4 & 103 & 37,3 & 60 & 23,0 & \\
\hline 45 or more & 176 & 32,8 & 88 & 31,9 & 88 & 33,7 & \\
\hline \multicolumn{8}{|l|}{ Marital Status } \\
\hline Single & 166 & 30,9 & 68 & 24,6 & 98 & 37,5 & 0.008 \\
\hline Married & 327 & 60,9 & 185 & 67,0 & 142 & 54,4 & \\
\hline Widow & 28 & 5,2 & 13 & 4,7 & 15 & 5,7 & \\
\hline Divorced & 16 & 3,0 & 10 & 3,6 & 6 & 2,3 & \\
\hline \multicolumn{8}{|l|}{ Parity } \\
\hline No & 314 & 58,5 & 138 & 50,0 & 176 & 67,4 & $<0.0001$ \\
\hline $1-2$ & 138 & 25,7 & 73 & 26,4 & 65 & 24,9 & \\
\hline 3 or more & 72 & 13,4 & 56 & 20,3 & 16 & 6,1 & \\
\hline Missing & 13 & 2,4 & 9 & 3,3 & 4 & 1,5 & \\
\hline \multicolumn{8}{|c|}{ Head of the Family } \\
\hline No & 355 & 66,1 & 178 & 64,5 & 177 & 67,8 & 0.42 \\
\hline Yes & 182 & 33,9 & 98 & 35,5 & 84 & 32,2 & \\
\hline \multicolumn{8}{|l|}{ Education } \\
\hline High & 201 & 37,4 & 85 & 30,8 & 116 & 44,4 & 0.0007 \\
\hline Low & 333 & 60,2 & 191 & 69,2 & 142 & 54,4 & \\
\hline Missing & 3 & 0,6 & 0 & 0 & 3 & 1,2 & \\
\hline \multicolumn{8}{|c|}{ Occupational Status } \\
\hline Employed & 363 & 67,6 & 166 & 45,7 & 197 & 75,5 & 0.005 \\
\hline Unemployed & 38 & 7,1 & 22 & 8,0 & 16 & 6,1 & \\
\hline Housewife & 134 & 25,0 & 87 & 31,5 & 47 & 18,0 & \\
\hline Missing & 2 & 0,4 & 1 & 0,4 & 1 & 0,4 & \\
\hline \multicolumn{8}{|l|}{ Migration } \\
\hline No & 158 & 29,4 & 66 & 23,9 & 92 & 35,2 & 0.004 \\
\hline Yes & 379 & 70,6 & 210 & 76,1 & 169 & 64,8 & \\
\hline \multicolumn{8}{|c|}{ Place of Residence } \\
\hline Brasília & 194 & 36,1 & 123 & 44,6 & 71 & 27,2 & $<0.0001$ \\
\hline São Paulo & 142 & 26,4 & 52 & 18,8 & 90 & 34,5 & \\
\hline Porto Alegre & 201 & 37,4 & 101 & 36,6 & 100 & 38,3 & \\
\hline
\end{tabular}


Table 3. Association between Gender and Minor Psychiatric Morbidity, in Each Strata of Sociodemographic Variables.

Adjusted Odds-Ratios ${ }^{a}$ and 95\% Confidence Intervals, Likelihood Ratio Test ${ }^{b}$, Degrees of Freedom, and

\begin{tabular}{|c|c|c|c|c|}
\hline \multicolumn{5}{|c|}{$P$-Value for the Interaction Term ${ }^{C}$} \\
\hline Strata & $\begin{array}{l}\text { OR }(95 \% \mathrm{Cl} \text { ) between } \\
\text { Gender and MPM }\end{array}$ & LRT & $D F$ & $P$-Value \\
\hline \multicolumn{5}{|l|}{ Age Group } \\
\hline 14-29 & 2.33 (1.19-4.55) & 6.01 & 2 & 0.05 \\
\hline $30-44$ & $6.85(2.86-16.41)$ & & & \\
\hline 45 or more & $7.47(2.90-19.22)$ & & & \\
\hline \multicolumn{5}{|l|}{ Marital Status } \\
\hline Single & $3.16(1.54-6.50)$ & 0.56 & 1 & 0.46 \\
\hline Married & $4.70(2.27-9.74)$ & & & \\
\hline \multicolumn{5}{|l|}{ Parity } \\
\hline No children & $3.71(2.12-6.48)$ & & & \\
\hline $1-2$ & $7.03(2.55-19.38)$ & 2.80 & 2 & 0.25 \\
\hline 3 or more & $1.87(0.45-7.80)$ & & & \\
\hline \multicolumn{5}{|c|}{ Head of the House } \\
\hline No & $3.60(1.92-6.77)$ & 0.21 & 1 & 0.65 \\
\hline Yes & $4.55(2.08-9.95)$ & & & \\
\hline \multicolumn{5}{|l|}{ Education } \\
\hline High & $4.48(2.40-8.37)$ & 0.42 & 1 & 0.52 \\
\hline Low & $3.36(1.68-6.71)$ & & & \\
\hline \multicolumn{5}{|l|}{ Migration } \\
\hline No & $3.02(1.45-6.30)$ & 0.90 & 1 & 0.34 \\
\hline Yes & $4.68(2.55-8.59)$ & & & \\
\hline \multicolumn{5}{|c|}{ Place of Residence } \\
\hline Brasília & 3.88 (1.88-8.03) & & & \\
\hline São Paulo & 3.54 (1.35-9.25) & 0.10 & 2 & 0.95 \\
\hline Porto Alegre & $4.25(2.08-8.69)$ & & & \\
\hline
\end{tabular}

${ }^{a}$ Adjusted for the other variables in the table plus occupational status.

Likelihood ratio test comparing the saturated model (including interaction term) with reduced model (without interaction term).

${ }^{c}$ Interaction terms including the variable occupational status were not analyzed because there was no convergence of the model. 
of interaction of gender with marital status, parity, level of education, being head of household, migration and city.

\section{DISCUSSION}

In this study women showed a higher risk of minor psychiatric morbidity (MPM) than men. Although the study was carried out in a different geographical and cultural context, this is consistent with most investigations carried out in the United States and Western European countries. On the other hand, the present study did not replicate the finding of marital status modifying the association between gender and MPM. In contrast we found this association was modified by age: the effect of gender on MPM was three times stronger among women over thirty compared to those under the age of thirty.

In the present study women suffered from MPM more than men independently of their marital status. This finding is not in agreement with the results of some studies that found that this higher risk was restricted to married women. How do we explain these findings? It is possible that marriage leads to different conditions in Brazil than it does in other countries reported in the literature. In other words, the conditions related to marriage that modify the association between MPM and gender in developed countries may not be associated with marriage or may not have the same impact on MPM in Brazil. An analysis on the interaction of marital status and socioeconomic variables on the risk of MPM in the same population used in the present study has been published elsewhere [23]. The results showed that people with low level of education were at higher risk of MPM if they were married than if they were single. As education can be regarded as a proxy for adversity in this country, we might suggest that in Brazil the burden of marriage is more related to socioeconomic adversities than gender characteristics.

The gender differential in MPM was not homogenous through age groups. Women had a risk of developing MPM two times greater than men under the age of thirty, and seven times when older than thirty. This finding was observed even after controlling for sociodemographic factors.

Few studies examined how the risk of MPM associated with gender changes with age. Jorm [24] found no gender difference in depression during childhood, greater prevalence in middle-aged women than in middle-aged men and, finally, a reduction in the female/male prevalence ratio in elder groups. In our investigation, the odds-ratio (female/male) increased after the age of thirty, with no evidence of change in the older age groups. There are at least two explanations for this difference. Jorm's study was restricted to the diagnosis of depression. In our investigation we used the category MPM, which includes the diagnosis of depression, but also anxiety, phobic and somatoform disorders. Even considering that our exploratory analysis showed a similar pattern of association between these nosologic categories and the variables investigated, it is possible that some 
particular features exist regarding the interaction of gender with age group related to affective disorders, which the present study did not have the statistical power to explore. Another possibility is that Jorm's population was, on average, older than in our study, and that the reduction in gender differential occurs in more advanced age groups.

Vazquez-Barquero et al. [5], studying a population from a rural area of Cantabria, found no evidence of interactive effect of gender with age. In their study, psychiatric morbidity was established by the PSE-CATEGO system. It is important to note that Vazquez-Barquero et al. stratified age in only two groups: less than forty-five and forty-five or more. Although one cannot rule out the lack of statistical power to detect the interaction, or a real absence of interaction effect of gender with age in that population, the way the authors built age categories might had some influence on their findings. We found no difference in the magnitude of the association between gender and MPM for the age groups thirty to forty-four and forty-five or more, and a re-analysis of our data according to the age groups used by Vazquez-Barquero et al. did not show the interaction found with our original stratification $(p=0.52)$. So it is possible that the way Vazquez-Barquero et al. stratified age diluted the modification effect of this variable in the association between gender and psychiatric illness.

Zunzunegui et al. [25] investigated gender differences in depressive symptoms among Spanish elderly living in a working-class city in the area of Madrid (Leganés). They found no statistically significant interaction of gender with age. We need to be cautious if we want to compare these findings with those previously presented, as the study was restricted to a population aged sixty-five or more. All the previous studies investigated populations of a wider range of age groups. The lack of interaction in the study of Zunzunegui et al. may be understood as a result of an investigation focused on a more restricted and homogeneous group.

How could we explain our finding that the differential in female/male risk of MPM was higher for women older than thirty. Social theories, including the role of life events and social support [26], perception of low social control [27] and fatalistic perception [28] have been proposed to explain why women are more likely to suffer from MPM than men. These theories could be extended in an attempt to understand why this association was modified by age group. It is possible that women after the age of thirty are more likely to be exposed to stressful life events, to lose social support and/or to present more conflicts related to sex role, expressing an age effect.

Another possibility is that the age differences reflect not only an aging process, but also a cohort effect caused by successive generations having their specific experiences. People between fourteen and twenty-nine years old, in our study, were born after the sixties when important changes in female role began in Brazil. This cohort effect is consistent with findings showing that the prevalence of anxiety and depression is getting more similar in men and women in the recent 
generations in the United States [29]. Although we cannot rule out the hypothesis that older men are more reluctant to refer MPM symptoms, the idea that older women (women from older generations) have lower perceived control over the social environment and/or a more fatalistic view in the presence of adversity is consistent with cultural and social life of Brazil today. Moreover, both characteristics have been related to anxiety and depression [27, 28].

Gender itself is a complex variable with a biological component and other elements strongly influenced by social and cultural environment. We propose that the effect of these variables that modify the association between gender and MPM can differ from one country to another, and between social groups within the same country. Unfortunately, hypotheses on the effects of personal control or fatalistic perception have been less investigated than stressful life events and social support theories using data from general population. We recommend that the hypothesis that women from older generations would have low perceived control over the social environment in the presence of acute or chronic forms of stress constitutes an interesting and fruitful avenue of research to be explored in future studies. We further recommend that future studies of the effect of gender on MPM consider perceived control in framing their questions and interpreting their results.

\section{ACKNOWLEDGMENTS}

The authors acknowledge the invaluable institutional support of Marcos Pacheco de Toledo Ferraz, Marleide Motta Gomes and Eliane Seidl from the Mental Health Division (DINSAM) of the Ministry of Health. Vilma de Souza Santana collaborated with the elaboration of the research proposal and in planning the fieldwork of the pilot study. The Brasília staff was coordinated by Dr. Josimar Farias de França. The fieldwork was carried out by Marisa Pacini Costa and Alcinda Machado Godoi; Maria Inez Telles Walter was statistical consultant. The Porto Alegre staff was coordinated by Dr. Jefferson Gomes Fernandes and Dr. Ellis D'Arigo Busnello. Maria Inez Schmidt, Luciana Gigante, Sotero Serrate Mengue, Melaine Ogliari Pereira and Paulo Knapp collaborated with the fieldwork. The São Paulo staff was coordinated by Dr. Sérgio Baxter Andreoli and the fieldwork was assisted by Dr. Claudio Torres de Miranda, Márcia Menon, and Atilio Bombana.

\section{REFERENCES}

1. Weissman MM, Klerman G. Sex differences and the epidemiology of depression. Archives of General Psychiatry 1997;34:98-112.

2. Briscoe M. Sex differences in psychological well being. Psychological Medicine (monogr suppl) 1982;1:1-46. 
3. Jenkins R. Sex differences in minor psychiatric morbidity. Psychological Medicine (monogr suppl) 1985;7:1-53.

4. Regier DA, Boyd JH, Burke JD, et al. One-month prevalence of mental disorders in the United States. Archives of General Psychiatry 1988;45:977-986.

5. Vázquez-Barquero JL, Manrique JFD, Muñoz J, et al. Sex differences in mental illness: A community study of the influence of physical health and sociodemographic factors. Social Psychiatry and Psychiatric Epidemiology 1992;27:62-68.

6. Gallo JJ, Royall DR, Anthony JC. Risk factors for the onset of depression in middle age and later life. Social Psychiatry and Psychiatric Epidemiology 1993;28:101-108.

7. Weissman MM, Bland RC, Canino GJ, et al. Cross-national epidemiology of major depression and bipolar disorder. Journal of the American Medical Association 1996;276:293-299.

8. Bijl RV, Ravelli A, van Zessen G. Prevalence of psychiatric disorder in the general population: Results of the Netherlands mental survey and incidence study (NEMESIS). Social Psychiatry and Psychiatric Epidemiology 1998;33:587-595.

9. Goldberg D, Huxley P. Common mental disorders: A bio-social model. London: Routledge, 1992.

10. Finlay-Jones R, Burvill P. The prevalence of minor psychiatric morbidity in the community. Psychological Medicine 1977;7:475-489.

11. Cheng TA. A community study of minor psychiatric morbidity in Taiwan. Psychological Medicine 1988;18:953-968.

12. Mari JJ. Psychiatric morbidity in three primary care clinics. Social Psychiatry, 1987;22:129-138.

13. Gove WR. The relationship between sex roles, mental illness and mental status. Social Forces 1972;51:34-44.

14. Tennant C, Bebbington P, Hurry J. Female vulnerability to neurosis: The influence of social roles. Australia New Zealand Journal of Psychiatry 1982;16:135-140.

15. Hafner RJ. Marriage \& mental illness. A sex role perspective. New York: The Guilford Press, 1986.

16. Bebbington PE, Dean GD, Hurry J, Tennant C. Gender, parity and prevalence of minor affective disorder. British Journal of Psychiatry 1991;158:40-45.

17. Almeida Filho N, Mari JJ, Coutinho ESF, et al. The Brazilian multicentric study of psychiatric morbidity: Methodological features and prevalence estimates. British Journal of Psychiatry 1997;171:524-529.

18. Santana VS. Estudo epidemiológico das doenças mentais em um bairro de Salvador. Salvador: Série de Estudos em Saúde (Secretaria de Saúde da Bahia), 1982.

19. Miranda C, Mari JJ, Jorge M, et al. Versão Brasileira do Inventário de Sintomas do DSM-III. São Paulo: Escola Paulista de Medicina, 1987.

20. American Psychiatry Association Diagnostic and Statistical Manual of Mental Disorders. Washington DC: APA, 1980.

21. EGRET_Epidemiological Graphics, Estimation and Testing Package. Seattle: Statistics and Epidemiological Research Corp. and Cytel Software, 1990.

22. Kleinbaum DG. Logistic regression. A self-learning text. New York: Springer-Verlag, 1994.

23. Coutinho ESF, Almeida Filho N, Rodrigues L, Mari JJ. A case-control study of social determinants of minor psychiatric morbidity in Brazil II: The effect of macro-social 
208 / COUTINHO ET AL.

variables. Presented at the Epid95-III Congresso Brasileiro de Epidemiologia, Salvador, Brasil, April 1995.

24. Jorm AF. Sex and age differences in depression: A quantitative synthesis of published research. Australia New Zealand Journal of Psychiatry 1987;21:46-53.

25. Zunzunegui MV, Béland F, Llácer A, León V. Gender differences in depressive symptoms among Spanish elderly. Social Psychiatry and Psychiatric Epidemiology 1998;33:195-205.

26. Eaton WW. The sociology of mental disorders. New York: Praeger Publishers, 1986.

27. Rosenfield S. The effects of women's employment: Personal control and sex differences in mental health. Journal of Health and Social Behavior 1989;30:77-91.

28. Wheaton B. The sociogenesis of psychological disorder: An attributional theory. Journal of Health and Social Behavior 1980;21:100-124.

29. Murphy JM. Trends in depression and anxiety. Acta Psychiatrica Scandia 1986; 73:113-127.

Direct reprint requests to:

Dr. Evandro Coutinho

Rua Leopoldo Bulhões 1480/8 $\supset$ andar

Manguinhos

Rio de Janeiro, Brazil 21041-210 